\title{
Benchmarking construction technology transfer in Thailand
}

Abstract: In an effort to more rapidly develop their infrastructure, economies and living standards, many newly industrialized countries, such as Thailand, have embarked on a series of international Technology Transfer (TT) initiatives within the construction and other industries. However, these initiatives have not immediately translated into enhanced capabilities and competitiveness within indigenous firms, resulting in a sustained reliance on foreign firms. With few clues as to why TT ventures have not created expected outcomes for the indigenous construction industry, newly industrialized countries lack direction on how to more rapidly diffuse best-practice technology. Management philosophies such as benchmarking and performance measurement have become essential activities for firms, across all industry sectors, to achieve continuous process improvement and maintain competitiveness in the global market. In an attempt to better diagnose the health of TT ventures and ultimately improve rates of TT, this paper promotes benchmarking as a tool for measuring baseline and future performance across a wide range of TT perspectives. Utilizing the results from a questionnaire survey of 162 industry professionals from Thailand, a TT performance measurement framework, consisting of eight diverse perspectives was formulated through exploratory factor analysis. These perspectives represent the enablers and outcomes of the TT process, namely: (1) technology characteristics; (2) government influence; (3) relationship building; (4) transferor characteristics; (5) transferee characteristics; (6) economic advancement; (7) knowledge advancement; and (8) project performance. The framework was utilized to provide a baseline benchmark index of TT performance in Thailand. A benchmark score of $70 \%$ was determined, implying that up to 2005 , construction TT ventures in Thailand have been operating moderately to highly effectively/successfully. Moreover, the TT performance of individual transferor nationalities operating in Thailand was compared. The study provides some evidence that Japanese construction firms are not only the leading exporter of construction services to Thailand but also perform slightly higher across TT performance perspectives influenced by the transferor.

Key words: Technology transfer, benchmarking, performance measurement, developing countries, Thailand 


\section{Introduction}

Over the last twenty years, the fast growing Asian region has experienced rapid industrialization and economic growth. Much of this change can be attributed to international technology transfer (Devapriya and Ganesan, 2002; Marton, 1986; Saad et al., 2002; Schnepp et al., 1990). The construction sector of Thailand is no exception, experiencing unprecedented growth through the formation of large building and infrastructure programs that are largely partnered with foreign enterprises. Such programs have undoubtedly escalated the turnover of the construction sector in Thailand. But the question remains, whether Thai construction professionals are gaining best-practice knowledge and technologies, ultimately reducing their reliance on foreign multi-nationals through the creation of internationally competent and competitive indigenous consultants and contractors. Project promoters and financiers, such as host governments and the World Bank, have a vested interest in ensuring that technology is being transferred at an acceptable rate. However, although technology transfer is touted as a key objective of large partnered infrastructure projects, they are often commissioned without any structured policies or guidelines for measuring the rates of TT diffusion to host individuals, firms and the industry at large. Benchmarking the performance of construction TT at these levels, provides opportunities for all project participants to better gauge deficiencies in the TT process and ensure that expected outcomes are being delivered. In an attempt to instil a culture of TT benchmarking in the construction industry, this paper addresses the first stage of the benchmarking process, through investigating the baseline performance of international TT ventures in the Thai construction sector. This baseline benchmark was constructed utilizing a framework, which includes a number of perspectives and associated indicators that capture all the enablers of the TT process and the value it has created for the host sector.

\section{Benchmarking technology transfer}

Over the last couple of decades, there has been considerable interest in the application of the benchmarking concept in construction. This interest is reflected in the reported literature, where benchmarking is addressed 
in the context of project duration (Walker, 1994), contractor selection (Palaneeswaran and Kumaraswamy, 2000), partnering performance (Li et al., 2001), information technology evaluation (Stewart and Mohamed, 2004) and safety management (Mohamed, 2003). However, to-date there has been few attempts to provide a baseline benchmark of the performance of TT ventures in construction. Such an exercise would require the development of a framework that provides more than a group of isolated and eventually conflicting measures and strategies. Moreover, the framework should track many of the principles of the Balanced Scorecard (Kaplan and Norton, 1992) which provides a holistic and value-based balanced report on the many facets of a process and its outcomes; providing a balance between short- and long-term objectives, between lagging and leading indicators, and between external and internal performance perspectives. This paper argues that by selecting and evaluating appropriate indicators, in each perspective, requirements can be identified, and actions to the identified goals can be aligned and facilitated. The proposed approach should consequently enable government and industry to pursue incremental TT performance improvements.

A literature review was undertaken in this study, which closely examined TT studies undertaken across all industry sectors with the view to develop a conceptual framework for benchmarking TT ventures in the construction sector. Such a framework should include perspectives and associated indicators addressing the TT process (enablers) and the outcomes derived (TT-value added to host sector). This will ensure that the framework incorporates both the leading and lagging indictors of TT implementation. The following sections provide the persuasion for an evaluation framework which includes seven proposed perspectives. In total, the conceptual framework includes four TT enablers, namely, transfer environment, learning environment, transferor (foreigner) and transferee (host) characteristics. The performance of, and interrelationship between, these enablers contributes to the degree of value added to the host construction sector in three main areas, namely, economic advancement, knowledge advancement and project performance. Figure 1 illustrates the seven proposed perspectives. Moreover, a summary of the developed perspectives with their associated indicators is presented in Table 1. 


\section{Transfer environment}

The transfer environment is focused at the macro level of a country and its respective Architecture, Engineering and Construction (AEC) sector, and is predominately concerned with the impact of country and project related factors on the TT process. This perspective includes four sub-factors namely, the complexity of construction technology utilized by the transferor, mode of transfer, government policy and enforcement practices. Firstly, it is essential that the construction technology used on the project is more advanced than the current working practices of the host workers but not too advanced that they will be unable to embrace it on future projects (Simkoko, 1992). Secondly, the construction mode of transfer adopted on the project can influence the degree to which TT performs. Typically, construction projects incorporating TT are procured by turnkey systems, direct licensing agreements, management contracting or joint ventures. For the larger and/or complex TT projects, alternative modes may be adopted such as licensing-cum joint venture, turnkeycum-licensing, etc. (Calantone et al., 1990). Finally, the host government's policies, regulations and enforcement practices can impact greatly on the effectiveness of TT initiatives, especially their international political system and domestic political structure (Calantone et al., 1990). Such policies should provide incentive to transferors to pro-actively disseminate knowledge to indigenous competitors (Kumaraswamy and Shrestha, 2002; Ofori, 2000).

\section{Learning environment}

The learning environment is concerned with the relationship and communication between the transferor and transferee, and the effectiveness of implemented transfer programs. Cultural characteristics and the distance between the technology provider and receiver is a major concern when managing international technology transfer (Fisher and Ranasinghe, 2001; Kumaraswamy and Shrestha, 2002; Lin and Berg, 2001). For TT to function properly the organizations involved in the process should try to build a culture of mutual trust through effective communication between transferor and transferee (Black et al., 2000; Malik, 2002). This culture can only be established through strong commitment from the senior management teams of both the host and foreign organizations (Black et al., 2000; Devapriya and Ganesan, 2002). Moreover, an effective 
learning environment will be more likely to occur when either or both the transferor and transferee have been experienced in TT or partnering projects in the past (Black et al., 2000). Lastly, TT programs on construction projects, which are formally planned and managed (i.e. training times allocated, supervision specified, etc.), are more likely to transfer a greater degree of knowledge to the host workers (Saad et al., 2001; Simkoko, 1992). Finally, an effective learning environment is pivotal for achieving TT, thus this perspective was placed at the centre of Figure 1.

\section{Transferor and transferee characteristics}

The remaining two enablers are related to the characteristics of the transferor and transferee. These enablers are concerned with the degree to which the characteristics of the transferor and transferee encourage the TT process (Kumaraswamy and Shrestha, 2002). Firstly, one of the essential elements to achieving successful TT is that the transferor is willing to transfer the appropriate technology and the transferee has every intention to adopt it (Malik, 2002). Secondly, the degree of international experience of both the transferor and transferee and the nature of this experience can impact significantly on the TT process (Lin and Berg, 2001). Moreover, the capacity to transfer and adopt technology will also depend on each individuals existing knowledge base and the gap between this knowledge level and the level required to utilize the transferred technology (Saad et al., 2002; Wang et al., 2004). Lastly, the appropriateness of the transferor and transferees cultural traits (i.e. leadership style, ego, etc.) for working in a partnership should be determined prior to embarking on the TT process (Kumaraswamy and Shrestha, 2002; Fisher and Ranasinghe, 2001; Wang et al., 2004).

\section{Economic advancement}

One of the predominant reasons why governments in developing countries encourage international TT initiatives is to improve their living standards and economic prospects. This bold objective can only be achieved if host workers and professionals perform at a higher level and become more competitive in the domestic and international market (Benedetto et al., 2003; Fisher and Ranasinghe, 2001). It should be noted 
here that economic advancement is a lagging factor that will typically occur in the long term once transferred knowledge has been absorbed and applied on a number of projects across the host country.

\section{Knowledge advancement}

Beyond the quantitative economic benefits achievable from TT, host AEC firms may also experience knowledge advancement at the individual and organizational level (Gilbert and Cordey-Hayes, 1996). The initial outcome of TT programs is the transfer of implicit and tacit knowledge to the host workers. This knowledge, if accepted, should lead to improve working practices in the immediate term and hopefully become the norm over the long term.

\section{Project performance}

It is generally accepted that the major objectives in construction projects are financial performance, schedule performance and quality performance. Improved performance in these key areas should result from effective technology transfer (Chua et al., 1999; Devapriya and Ganesan, 2002). This perspective is concerned with the impact of TT programs on the performance of AEC projects. Specifically, this perspective examines any improvements in the performance of financial, schedule and quality indicators.

Table 1 Technology transfer perspectives and indicators

(INSERT TABLE 1)

(INSERT FIGURE 1)

Figure 1 Seven proposed perspectives for benchmarking technology transfer 


\section{Research Method}

\section{Data collection instrument}

Data collection for this study was undertaken with Thai construction professionals in the second quarter of 2005. The target group of respondents includes design and construction professionals from construction projects involving TT initiatives. In total, 300 questionnaires were distributed and 162 were returned, representing a response rate of 54 per cent. The questionnaire survey contained three distinct sections. The first section solicited descriptive statistics on the participating respondents and the past and present projects that they have been involved with where TT programs were integrated. This section enabled the establishment of a comprehensive respondent profile (i.e. experience, position description, etc.) and TT project profile (i.e. value, type, mode of transfer, etc.). Section two included questions relating to the enablers for successful TT, including: transfer environment; learning environment; transferor characteristics and transferee characteristics. Section three focused on measuring the outcomes of the TT process in the following categories: economic advancement; knowledge advancement; and project performance. Sections two and three contained a total of 29 questions representing all the variables in the conceptual framework (Table 1). Respondents were requested to provide a rating for these variables in two separate columns (A and B) measured on a five-point Likert scale. Column A asked respondents for their opinion about statements related to TT, ranging from ' $1=$ strongly disagree' to ' $5=$ strongly agree'. These results were used to determine the importance/significance of each indicator. Column B sought to ascertain respondents' perception of the successfulness/effectiveness of TT perspectives in the construction environment, based on their experience. The scale of column B ranged from ' 1 = strongly negative' to ' $5=$ strongly positive'. These results were essential for determining the effectiveness of TT in the Thai construction industry. Ultimately, results were utilized to determine relative and global weights (column A) and performance ratings (Column B) for individual indicators, which culminated in the development of a TT index for Thailand. 


\section{Respondent profile}

The respondents were classified into six position categories: project manager (16\%); site engineer (40\%); consulting engineer (16\%); construction manager/foreman (16\%); architect (11\%); and other (1\%). The type of organisation they were employed included: main contractor $(43 \%)$; sub-contractor $(20 \%)$; consultant (35\%); and other (2\%). The respondents' age breakdown was: under 30 years (20\%); 30-40 years (37\%); 4050 years $(36 \%)$; and over 50 years $(7 \%)$. Their construction experience breakdown was: $0-5$ years $(24 \%)$; 610 years (19\%); $11-15$ years (24\%); $16-20$ years (17\%); and over 20 years (16\%). Evaluating education levels was necessary to demonstrate that the respondents were sufficiently educated to develop a professional opinion about the construction industry. The highest frequency of respondents had a bachelor degree (62\%). Masters degree qualified respondents was also quite common (27\%). Unexpectedly, very few respondents had less than a tertiary education in the AEC field (1\%).

\section{TT project profile}

Respondents were requested to detail the number of projects they have been involved with where TT was incorporated. More than half of the questionnaire participants have been involved with at least two past projects involving TT. Only one third of the sample has been involved in just one international TT project. This gives them a good basis for evaluating the importance and success of individual TT process and outcome indicators. Understandably, very few (about 6\%) participated in more than ten international TT projects. Respondents were requested to provide a range of information on the last three construction projects they have been involved in where TT from a foreign partner was integrated (Figure 2). In total, the respondents provided detailed information on 280 projects constructed in Thailand. The information collected for these projects included year completed, project description, project value, transferor nationality, skills transferred, mode of transfer and a general rating on the success of the project. A descriptive summary for each of these items is provided in the following paragraphs and a summary illustrated in Figure 2. It should be noted, that in Figure 2, the 2005-2009 category only includes recently completed projects and is not representative of the total number of projects that will be completed in this period. 
The type of projects undertaken for specific time periods was examined and the results were classified into five main categories: residential building; commercial building; industrial building; civil engineering project; and transportation infrastructure. Figure 2(a) details the type of projects completed, grouped into five-year categories, from 1970 till 2009. In recent years (2000-2004), there was an unprecedented increase in the number of transportation infrastructure and civil engineering projects constructed in Thailand. Understandably, efficient transport systems, water treatment facilities, waste management systems, and other civil engineering works are typically one of the initial requirements of a newly industrialized country. Adversely, technology was rarely transferred to the less complex residential construction sector over the last 30 years in Thailand. This may be due to the competitive nature of this sector and the reduced desire of local contractors to enhance their skills. Figure 2(b) details the cost breakdown for each listed project. Most construction technology was transferred on the large-scale infrastructure projects with a value greater than fifty million U.S. dollars (> 2000 million Thai Baht).

Additionally, the nationality of the technology transferor (i.e. foreigner) for each of the 280 listed projects was requested. Japan were involved in the highest numbers of projects (37\%), followed by Germany (21\%), U.S.A. (16\%), other countries (15\%), United Kingdom (8\%) and Australia (3\%). Other transferor nationalities included French, Taiwanese, Chinese, and Danish, to name a few. This result confirms comments made by Raferty et al. (1998) which describes Japan as an international leader in the provision of construction services. However, carefully examining Figure 2(c), it becomes evident that the recent growth (1995-present) in the market has enticed other nationalities, particularly German and U.S.A firms to become more aggressive, thus slowing eroding Japans slice of the total market share. The primary mode of transfer for construction projects where TT was implemented was joint venture (39\%), closely followed by turnkey (37\%). This trend reinforces other studies reported in the literature (Calantone et al., 1990). Management contracting was the next highest mode of transfer (23\%) followed by other modes of transfer (1\%: 3 projects). Figure 2(d) details the mode of transfer utilized by each transferor nationality. It does not appear that certain nationalities favour a particular mode of transfer. 
There were four groupings of skills transferred during the TT process including management, technical, new technology and other. Technical skills were predominately transferred $(43 \%)$, followed by management and new technology skills, both being transferred on 27 per cent of the projects. Skill types other than those previously mentioned (e.g. research and development) were transferred on only three per cent of the projects. Most projects examined transferred more than three types of skill. To gain a very general idea on the success of TT on individual projects the respondents were requested to provide a rating from very low (1) to very high (5). The majority of projects were rated as having moderate to very high success $(87 \%)$ with only a fraction indicating a low to very low success rating $(13 \%)$.

(INSERT FIGURE 2)

Figure 2 TT project profile (1970-2009)

\section{Data analysis and results}

\section{Analysis of variance}

Analysis of variance (ANOVA) was performed to ensure that respondents having different positions (e.g. site engineer, consultant, etc.) and from different types of organizations (contractor, consultant, etc.) could be considered as a single sample. ANOVA confirmed congeners between position types at the 0.05 level of significance (Black et al., 2000). However, for the type of organization, there were two variables, namely, willingness to implement $(p=0.022)$ and financial performance $(p=0.002)$, which had a significantly $(p<$ 0.05) different mean value for two organization types (main contractor, sub-contractor). Carefully examining mean values for these variables within their respective groups, it appears that sub-contractors do not believe that TT is being transferred to their level and will not help their financial performance. It should be noted that international TT typically involves only the larger contractors and consultants, thus many subcontractors perceive that TT will not generate any value for them. Since this variance was not widespread and only resulted in two combinations the data was treated as one useable sample. 


\section{Factor analysis}

Exploratory principal component factor analysis, with varimax rotation, was conducted to condense the information contained in the original 29 indicators into a smaller set of factors with a minimum loss of information (Hair et al., 1998; Hatcher, 1994). Specifically, the aim was to search for and define the fundamental perspectives assumed to underlie the original indicators. The data sample was deemed adequate for factor analysis, exceeding the observation to variable ratio (i.e. 5.6:1) recommended by Hair et al. (1998). Moreover, the value for the Kaiser-Meyer-Olkin measure of sampling adequacy was 0.84 , exceeding the recommended threshold level of 0.5 (Coakes, 2005). Factor analysis retained a 20 indicator solution, removing a total of 9 indicators. Two of the removed indicators (i.e. culture and training) had very high loadings within their own individual perspectives. These indicators could be argued as being essential enablers in the TT process; however, they were removed because they were perspectives which consisted of only one generic indicator. The implications of the removal of these indicators are discussed in a later section of this paper.

Eight (8) perspectives (factors) best represented the data in terms of variance explained (77\%) and grouping of indicators. These perspectives included: (1) technology characteristics (TC); (2) government influence (GI); (3) relationship building (RB); (4) transferor characteristics (TR); (5) transferee characteristics (TE); (6) economic advancement (EA); (7) knowledge advancement (KA); and (8) project performance (PP). Table 2 details the factor loading, explained variance, eigenvalues and Cronbach's alpha for the eight-factor solution. All factor loadings exceeded the 0.5 threshold level with loadings ranging from 0.64 to 0.80 . Additionally, Cronbach's alpha results ranged from 0.57-0.86 indicating that the scale used was reliable (Fang et al., 2004; Hatcher, 1994; Zain et al., 2005). The results underline that the transferor characteristics perspective is the key enabler of the TT process explaining almost half $(35 \%)$ of the total variance in the data set $(77 \%)$. The combined explained variance for the project-level enablers (i.e. transferor and transferee characteristics, relationship building) equates to more than two-thirds (53\%) of the total variance (77\%). These are undoubtedly, the perspectives that need to be carefully managed to ensure that the TT process 
derives the most value for the host country. The last three of these perspectives (6-8) are related to the outcomes derived from TT and explained 15 per cent of the variance in the data.

Table 2 Varimax rotated factor loading for the eight-factor solution (INSERT TABLE 2)

\section{Evaluating TT indicators}

The mean and standard deviation for the 20 refined TT performance indicators are detailed in Table 3. As previously described, column A was concerned with the importance/significance of indicators and column B with the success/effectiveness of them, according to the experience of the Thai respondent. The significant outcomes of this analysis are briefly summarized below. A complete discussion on the implications of TT performance ratings is provided in a later section.

Importance ratings: The mean values for all indicators in column A were greater than three (3.0) indicating that respondents perceived that all of the TT performance indicators were important. Relationship building (RB: 4.05) was considered to be the most important TT perspective. However, many of the other perspectives were considered almost equally important (TR, TE, EA, KA and PP). Perhaps due to respondents' limited understanding on the impact of macro factors on the TT process, technology characteristics (TC: 3.42 ) and government influence (GI: 3.45) were not considered to be as important. Most of the TT value creation indicators (EA, KA and PP) were deemed highly and equally important. However, the importance of TT for improving the financial performance of host firms was notably lower (PP1: 3.47) than the other outcome indicators.

Success ratings: Based on their experience, the respondents rated the transferor characteristics (TR: 3.62), relationship building (RB: 3.62) and transferee characteristics (TE: 3.60) perspectives as being the most successful. Communication was not only perceived as the most important indicator but was also rated as the most effective (RB3: 3.92). This result is promising, considering the variety of nationalities involved in TT 
projects in the Thai construction sector. The respondents indicated that TT was providing moderate to high value for the three value creation perspectives (EA: 3.55; KA: 3.44; PP: 3.34). However, they did not believe that TT initiatives were contributing to improved financial outcomes (PP1: 3.24).

Table 3 Perspective and indicator mean and standard deviation (INSERT TABLE 3)

\section{Evaluating transferor nationalities}

As mentioned above, the respondents provided information on a total of 280 projects that they have been involved with where TT was implemented. Moreover, for each of these projects they detailed the nationality of the transferor involved. In cases where the questionnaire respondent had only worked with one transferor nationality, we can assume that their ratings of the effectiveness/success of individual indicators also relate to that particular transferor. Data mining determined that three adequately sized $(N>10)$ samples could be developed, namely, Japan $(N=45)$, Germany $(N=26)$ and U.S.A. $(N=11)$. Although these samples are not of a sufficient size to undertake any meaningful statistical comparative analysis (i.e. $t$-tests), they provide clues as to which transferors are perceived to have better attributes for the transfer process and deriving outcomes for the host construction sector. Since three of the perspectives (i.e. GI, TC and TE) are largely based on host influences, mean and standard deviation values are only provided for the five remaining perspectives, which the transferor can significantly influence (Table 4). Thai construction professionals perceive that Japanese have the best characteristics for technology transfer, relationship building and creating TT-induced value. Japanese firms scored the highest mean values for all five perspectives with an overall mean value of 3.62. Notably, for the transferor characteristics perspective, the Japanese mean value was higher (3.70) than the other nationalities, particularly USA who scored a lower mean value (3.29). Whilst it appears that the Germans scored higher than U.S.A. for the two TT process enabling perspectives (i.e. RB, TR), the opposite is true for the outcome perspectives (EA, KA, PP), resulting in these nationalities having similar overall means. A comprehensive comparison between the three analyzed transferors is provided in 
the following section. Finally, readers should keep in mind the relatively small spread of mean scores when formulating opinions about particular transferor nationalities.

Table 4 Perspective and indicator mean and standard deviation - transferor nationality (INSERT TABLE 4)

\section{Benchmarking technology transfer performance}

The eight developed enabling and outcome perspectives were utilized as a framework to provide a benchmark of the current effectiveness of international construction TT ventures in Thailand. Moreover, a benchmark score was determined for the three above-mentioned nationalities. The mean importance/significance values for each indicator (Table 3: column A) was used to create relative and global weights for each indicator in the framework. The mean effectiveness/success values for each indicator (Table 3: column B) was then multiplied by relative and global weights to create individual perspective scores and an overall score, respectively. Table 5 details each indicators relative and global weighting, resultant performance scores for each perspective and the overall TT index for Thailand. Each of these benchmarking calculations and the implications of results are discussed in the following sections.

\section{Determining relative and global weights}

Prior to evaluating technology transfer, the relative and global weights were determined (Table 5). Relative weights $\left(r_{\mathrm{i}}\right)$ of perspectives were determined through consultation with a group of Thai construction professionals $(N=15)$. Through group consensus, they established each perspectives weighted contribution to the overall TT index. Transferor characteristics were determined to be the most important perspective (20\%), closely followed by transferee characteristics and relationship building (15\%). The remaining perspectives each had an importance weighting of ten per cent. Relative weights of indicators were determined utilizing importance scores solicited from questionnaire respondents. However, simply normalizing mean scores would not provide a representative differentiation between indicators. Many of the 
respondents provided a neutral rating (i.e. 1: strongly disagree SD; 2: disagree $\mathrm{D}$; 3: neutral N; 4: agree A; 5: strongly agree SA) for indicators which resulted in a small range of mean values; and ultimately similar relative weightings. To ensure a better distinction between indicators, the frequency distribution of mean values was multiplied by a different scaler $[-2,-1,0,1,2]$ and then normalized, thus removing neutral ratings. For example, indicator TC1 had a mean importance frequency distribution of [SD: 1, D: 17, N: 61, A: 69, SA: 14]. Multiplying this distribution by the scaler resulted in a value of 78 [i.e. $(1 \times-2)+(17 \times-1)+$ $(61 \times 0)+(69 \times 1)+(14 \times 2)=78]$. Similarly, for indicator TC2 the calculated value was 58 . Normalizing these two values [i.e. $r_{\mathrm{TC} 1}=78 \div(58+78)=0.57$ ] provides the relative weights for the two indicators from the technology characteristics perspective. Table 5 details the relative weights for all twenty indicators. Global weights $\left(k_{\mathrm{i}}\right)$ were obtained by multiplying the relative weight of a TT indicator by the relative weight of its parent perspective (Table 5). For example, the global weight for indicator TC1 was calculated as 0.057 $\left(k_{\mathrm{TC} 1}=0.1 \times 0.57=0.057\right)$. Thus, this indicator contributes almost six per cent to the overall TT index. In summary, relative weights were used to calculate scores for the eight perspectives and global weights for calculating the TT index.

\section{Evaluating technology transfer}

To provide a baseline benchmark on the performance of construction technology transfer in Thailand a score was calculated for each perspective of the framework and an overall TT index (Table 5). Perspective scores were calculated by summing the weighted result $r_{\mathrm{i}}\left(x_{\mathrm{i}}\right)$ for each indicator within a perspective (i.e. TC $=1.85$ $+1.44=3.29$ or $66 \%)$. The overall TT index was calculated by summing the weighted global result $k_{\mathrm{i}}\left(x_{\mathrm{i}}\right)$ for each indicator (i.e. TT index $=0.1847+\ldots+0.2030=3.5067$ or $70 \%$ ). A benchmark score of 70 per cent implies that to-date (2005) construction TT ventures in Thailand have been operating moderately to highly effectively/successfully. However, this result also demonstrates that there is much potential for improvement. It should be noted that this overall rating provides a more holistic view on TT performance by encapsulating both process enabling (i.e. TC, GI, RB, TR, TE) and outcome (KA, EA, PP) perspectives. Figure 3(a) provides clues on underperforming elements in the TT value creation process. Results for each perspective ranged from 66-73 per cent. Surprisingly, the two highest performing perspectives were transferor 
characteristics and relationship building (73\%) indicating that Thai professionals were satisfied with their foreign partners' characteristics and developed effective relationships with them. Adversely, the lowest performing perspectives were government influence and technology characteristics (66\%), suggesting that governments could formulate more receptive TT policy which encourages or dictates TT arrangements and modes of transfer; ultimately promoting better international relationships.

\section{(INSERT TABLE 5)}

Table 5 Evaluating technology transfer - baseline score

\section{Transferor nationality comparative analysis}

The above-mentioned method was utilized to benchmark the performance of individual transferor nationalities. This was achieved by replacing mean TT performance scores for the five influenced perspectives (TR, RB, EA, KA and PP) with those from each transferor sample (Table 4). Figure 3(b), (c) and (d) detail the resulting TT performance score for each framework perspective and the overall TT index for Japan, Germany and the U.S.A., respectively. Moreover, a histogram showing scores for the five perspectives influenced by the transferor is provided, to gain a better depiction of comparative performances (Figure 4). This figure illustrates that Japanese firms were perceived to be the most effective for transferring construction technology in Thailand. Specifically, they have achieved higher scores in the relationship building and transferor characteristics perspectives. Undoubtedly, Japans higher scores may have resulted from the following three predominant factors: (1) they have a greater inclination to develop alliance-based relationships with project partners; (2) the cultural distance between Thai and Japanese firms would be expected to be lower than with western firms; and (3) Japanese firms have been the most dominant exporter of construction services in the Asian market for a number of years. Also, this study provides some evidence that Japanese firms have grasped the lion's share of the Thai construction market through creating unyielding relationships with indigenous firms and by establishing a superior track record for transferring technology. Raferty et al. (1998) confirms Japans dominance as an exporter of construction services in Asia. In an attempt to increase their market share and rates of technology transfer, other construction exporters to 
Thailand, who predominately have Western/European cultural traits and approaches, could consider emulating aspects of the Japanese approach to technology transfer. Finally, readers should be mindful of the relatively small sample sizes for each transferor nationality, when making judgements on the influence of transferor nationality on TT performance.

\section{(INSERT FIGURE 3)}

Figure 3 Spider diagram showing the performance score for each framework perspective

\section{(INSERT FIGURE 4)}

Figure 4 Comparative performance scores for perspectives influenced by transferor nationality

\section{Future research}

This study represents the first stage of a comprehensive investigation on the application of benchmarking for international construction technology transfer in developed and newly-industrialized countries. Four research stages remain, including: (1) improving framework robustness; (2) modelling the cause-and-effect between framework perspectives and indicators; (3) strengthening the benchmarking methodology; and (4) conducting a longitudinal study on the performance of TT in Thailand. Each of these stages will be briefly described.

Firstly, whilst the developed framework encapsulates many elements of the TT process and its' outcomes, other perspectives and indicators require consideration in future revisions. As previously mentioned, two indicators with high factor loadings (i.e. culture and training) were removed from the framework. Undeniably, better management of cultural differences between the technology provider and receiver is essential for creating harmonious relationships, mutual trust and teamwork. Moreover, incorporating training sessions into TT agreements will not only foster mutual trust, communication and information sharing between the transferor and transferee, but will more rapidly advance local workers knowledge at the operational, functional and management levels. 
Secondly, the cause-and-effect between the developed framework perspectives will be determined through structural equation modelling. This proposed structural model will be invaluable to project promoters seeking to improve levels of technology diffusion in the construction sector of their country. Whilst TT performance scores across the eight perspectives provide clues as to where deficiencies in the TT process may have originated, they do not indicate the most appropriate paths to achieving higher TT-induced value creation. A structural model will provide promoters with some insight into the causal nature and strength of identified relationships, thus providing a roadmap for delivering future technology transfer strategies.

Thirdly, the benchmarking method adopted in this paper could be strengthened in a number of areas. The analytical hierarchy process (AHP) would provide better relative and global weights of perspectives and indicators. In this study, indicators were evaluated through a qualitative assessment scale. Future benchmarking investigations should include some quantitative TT performance indicators to provide a more accurate representation of the effectiveness/success of a TT process or outcome. For example, financial performance could be better evaluated by examining profit and cash-flow values in indigenous firms. Lastly, purpose-built methodologies will be developed for benchmarking at the project, sector and industry levels.

Finally, once the framework has been enhanced, a structural model developed and a comprehensive benchmarking method formulated, a series of TT performance benchmarking investigations will be undertaken in Thailand over a ten year period. This longitudinal study will enable promoters to evaluate improvements in levels of TT performance across each perspective and their associated indicators. Such results could provide evidence for connecting different TT approaches or strategies with resulting outcomes. For example, improvements in TT performance scores in one or more perspective could be linked with better technology transfer policies, if they were implemented between two measurement periods. 


\section{Conclusion}

Yearly, billions of dollars are funneled into infrastructure projects in developed and newly-industrialized countries. Most of these projects are financed by host governments and/or the international monetary fund under the assumptions that invested monies will not only provide essential infrastructure, but transfer advanced technologies to the indigenous workforce. Technology transfer initiatives have been in effect for a number of years, in countries like Thailand, with limited evidence that they have achieved envisaged objectives. Project promoters have a vested interest in creating a systematic approach to monitoring the effectiveness/success of technology transfer ventures. Benchmarking and performance evaluation approaches provide the means to identify underperforming processes and practices, re-engineer them utilizing bestpractice techniques, and create paths for achieving continuous process improvement.

This article argues, that evaluating the baseline performance of construction TT ventures in Thailand, is undeniably the first step to benchmarking technology transfer. A benchmark score of 70 per cent was determined, implying that up to 2005 , construction TT ventures in Thailand have been operating moderately to highly effectively/ successfully. The study also provides some evidence that Japanese construction firms are not only the leading exporter of construction services to Thailand but also perform slightly higher across TT performance perspectives influenced by the transferor. However, caution should be taken when framing opinions about particular transferor nationalities due to the relatively small and varied sample sizes (i.e. transferor nationality mean score differences are not statistically significant).

It is hoped that this research has inspired others to instigate the benchmarking of construction TT ventures in other countries, with the view to encourage government and industry to heighten their expectations on rates of transfer. Developed and newly-industrialized countries which better measure and manage TT ventures should achieve higher rates of transfer, ultimately, improving the quality of life of their people; a noble objective. 


\section{References}

Benedetto, C.A.D., Calantone, R.J. and Zhang, C. 2003: International technology transfer: model and exploratory study in the people's Republic of China. International Marketing Review 20(4), 446-462.

Black, C., Akintoye, A. and Fitzgerald, E. 2000: An analysis of success factors and benefits of partnering in construction. International Journal of Project Management 18(6), 423-434.

Calantone, R., Lee, M.T. and Gross A.C. 1990: Evaluating international technology transfer in a comparative marketing framework. Journal of Global Marketing 3(3), 23-46.

Chua, D.K.H., Kog, Y.C. and Loh, P.K. 1999: Critical success factors for different project objectives. Journal of Construction Engineering and Management 125(3), 142-150.

Coakes, S.J. 2005: SPSS analysis without anguish: version 12.0 for Windows. Australia: John Wiley \& Sons Australia Ltd.

Devapriya, K.A.K. and Ganesan, S. 2002: Technology transfer through subcontracting in developing countries. Building Research and Information 30(3), 171-182.

Fang, D.P., Xie, F., Huang, X.Y. and Li, H. 2004: Factor analysis-based studies on construction workplace safety management in China. International Journal of Project Management 22(1), 43-49.

Fisher, T.F. and Ranasinghe, M. 2001: Culture and foreign company's choice of entry mode: the case of the Singapore building and construction industry. Construction Management and Economics 19(4), 343-353.

Gilbert, M. and Cordey-Hayes, M. 1996: Understanding the process of knowledge transfer to achieve successful technological innovation. Technovation 16(6), 301-312. 
Gold, A.H., Malhotra, A. and Segars, A.H. 2001: Knowledge management: an organizational capabilities perspective. Journal of Management Information Systems 18(1), 185-214.

Hair, J.F., Anderson, R.E., Tatham, R.L. and Black, W.C. 1998: Multivariate data analysis. USA: Prentice-Hall.

Hatcher, L. 1994: A step-by-step approach to using the SAS system for factor analysis and structural equation modeling. USA: SAS Institution Inc.

Kaplan, R.S. and Norton, D.P. 1992: The balanced scorecard - measures that drive performance. Harvard Business Review 70(1), 71-79.

Kumaraswamy, M.M. and Shrestha, G.B. 2002: Targeting 'technology exchange' for faster organizational and industry development. Building Research and Information 30(3), 183-195.

Li, H., Cheng, E.W.L., Love, P.E.D. and Irani, Z. 2001: Co-operative benchmarking: a tool for partnering excellence in construction. International Journal of Project Management 19(3), 171-179.

Lin, B.W., and Berg, D. 2001: Effects of cultural difference on technology transfer projects: an empirical study of Taiwanese manufacturing companies. International Journal of Project Management 19(5): 287-293.

Makilouko, M. 2004: Coping with multicultural projects: the leadership styles of finish project managers. International Journal of Project Management 22(5): 387-396.

Malik, K. 2002: Aiding the technology manager: a conceptual model for intra-firm technology transfer. Technovation 22(7), 427-436. 
Marton, K. 1986: Multinationals, technology and industrialization. USA: Lexington.

Mohamed, S. 2003: Scorecard approach to benchmarking organizational safety culture in construction. Journal of Construction Engineering and Management 129(1), 80-88.

Ofori, G. 2000: Globalization and construction industry development: research opportunities. Construction Management and Economics 18(3), 257-262.

Palaneeswaran, E. and Kumaraswamy, M.M. 2000: Benchmarking contractor selection practices in public-sector construction - a proposed model. Engineering, Construction \& Architectural Management 7(3), 285-299.

Raftery, J., Pasadilla, B., Chiang, Y.H., Hui, E.C.M. and Tang, B.S. 1998: Globalization and construction industry development: implications of recent developments in the construction sector in Asia. Construction Management and Economics 16(1), 729-737.

Saad, M., Cicmil, S. and Greenwood M. 2002: Technology transfer projects in developing countries furthering the project management perspectives. International Journal of Project Management 20(8): 617625.

Schnepp, O., Von Glinow, M.A. and Bhambri, A. 1990: United States-China technology transfer. USA: Prentice-Hall.

Simkoko, E.E. 1992: Managing international construction projects for competence development within local firms. International Journal of Project Management 10(1), 12-22.

Stewart, R.A. and Mohamed, S. 2004: Evaluating web-based project information management in construction: capturing the long-term value creation process. Automation in Construction 13(4), 469-479. 
Walker, D.H.T. 2004: An investigation into factors that determine building construction time performance. PhD thesis: Royal Melbourne Institute of Technology, Melbourne, Australia.

Wang, P., Tong, T.W. and Koh, C.P. 2004: An integrated model of knowledge transfer from MNC parent to China subsidiary. Journal of World Business 39(2), 168-182.

Zain, M., Rose, R.C., Abdullah, I. and Masrom, M. 2005: The relationship between information technology acceptance and organizational agility in Malaysia. Information \& Management 42(6): 829-839. 
Figure 1 Seven proposed perspectives for benchmarking technology transfer

Figure 2 TT project profile (1970-2009)

Figure 3 Spider diagram showing the performance score for each framework perspective

Figure 4 Comparative performance scores for perspectives influenced by transferor nationality

Table 1 Technology transfer perspectives and indicators

Table 2 Varimax rotated factor loading for the eight-factor solution

Table 3 Perspective and indicator mean and standard deviation

Table 4 Perspective and indicator mean and standard deviation - transferor nationality

Table 5 Evaluating technology transfer - baseline performance 


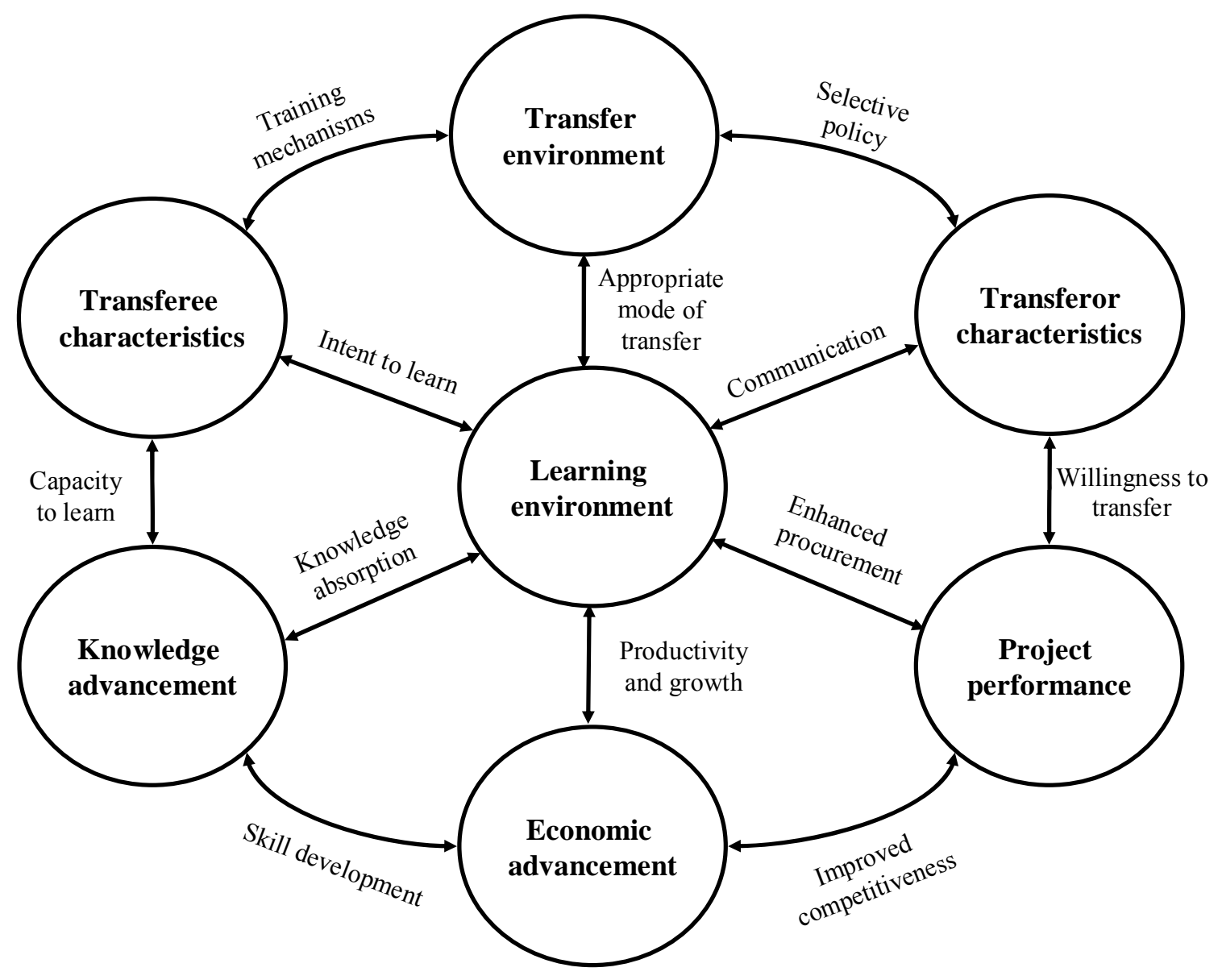

Figure 1 Seven proposed perspectives for benchmarking technology transfer 

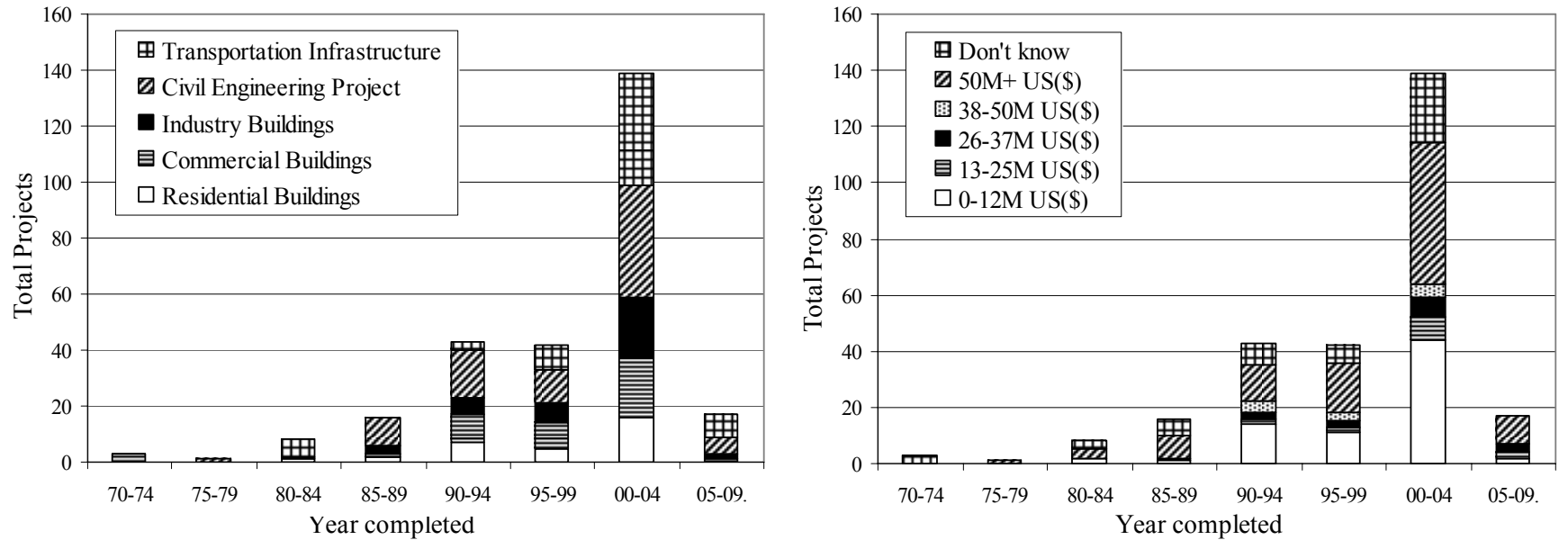

(a) Project type

(b) Project value

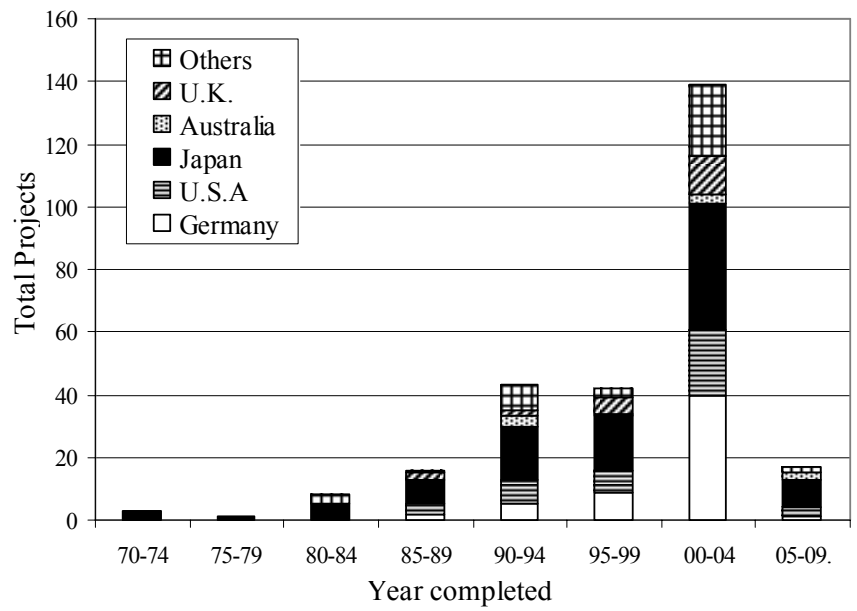

(c) Transferor nationality

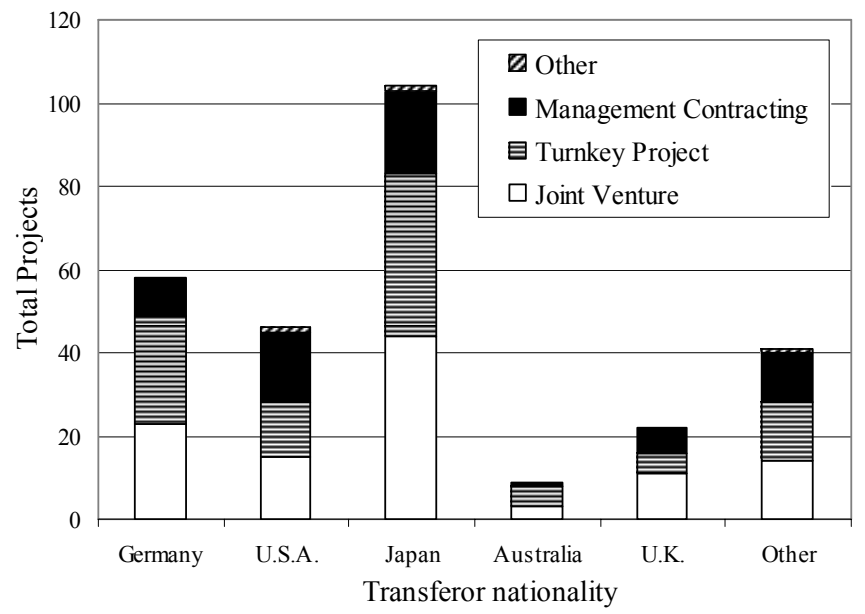

(d) Mode of transfer

Figure 2 TT project profile (1970-2009) 


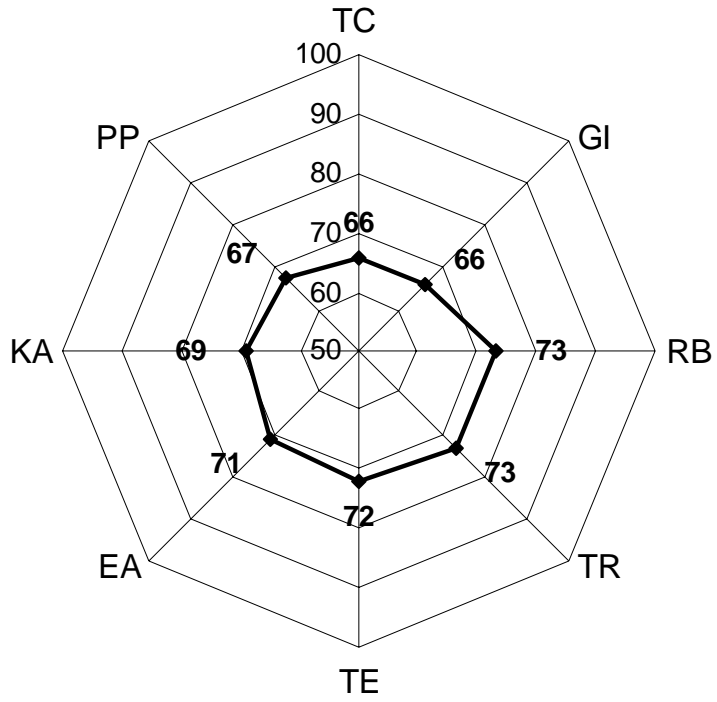

(a) Thailand: TT Index $=70$

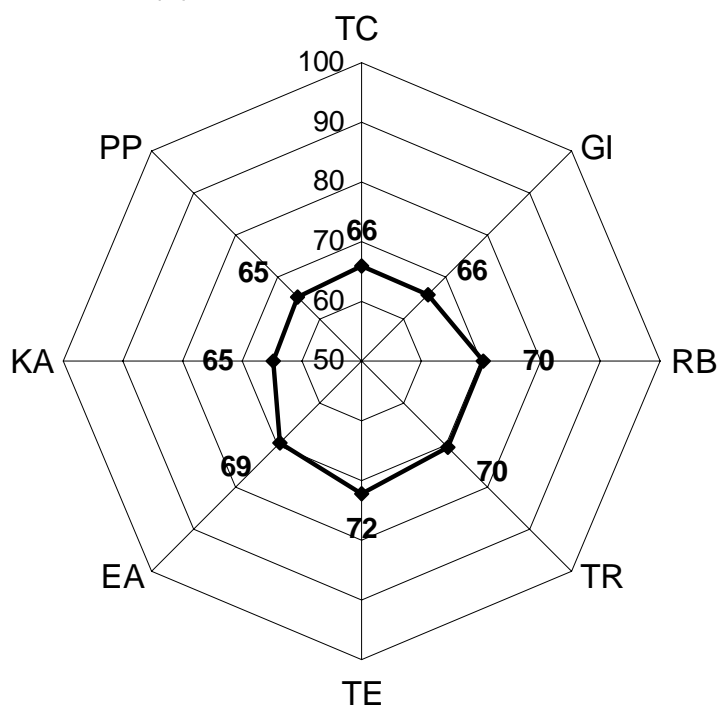

(c) Germany: TT Index $=69$

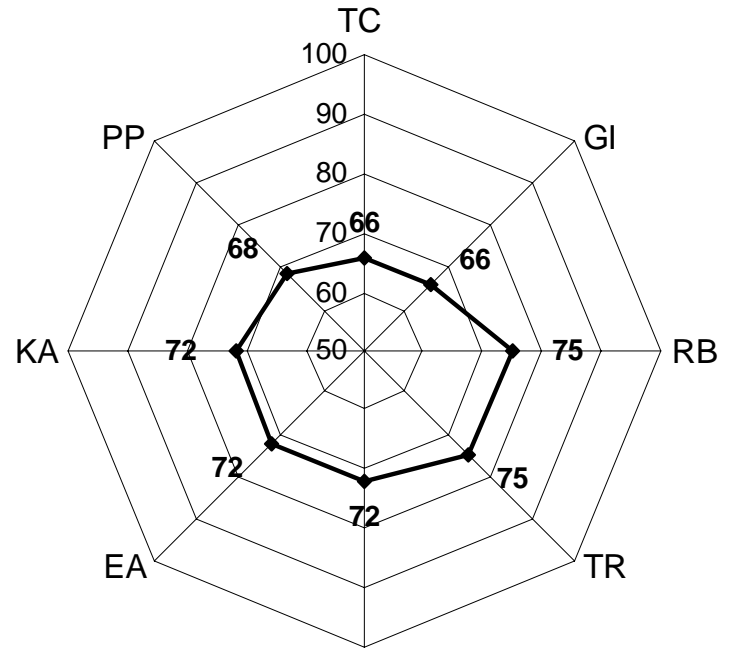

TE

(b) Japan: TT Index $=71$

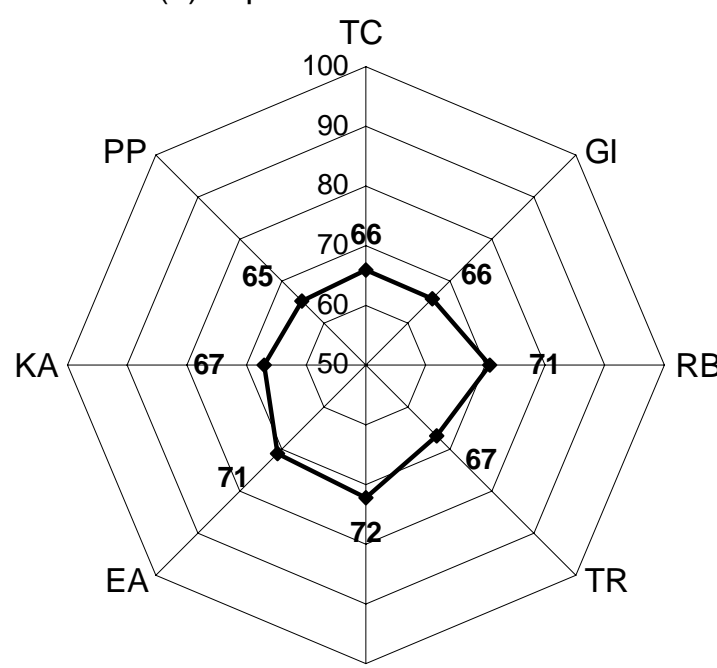

TE

(d) U.S.A.: TT Index $=68$

Key: TC: technology characteristics; GI: government influence; RB: relationship building; TR: transferor characteristics; TE: transferee characteristics; EA: economic advancement; KA: knowledge advancement; and PP: project performance.

Figure 3 Spider diagram showing the performance score for each framework perspective 


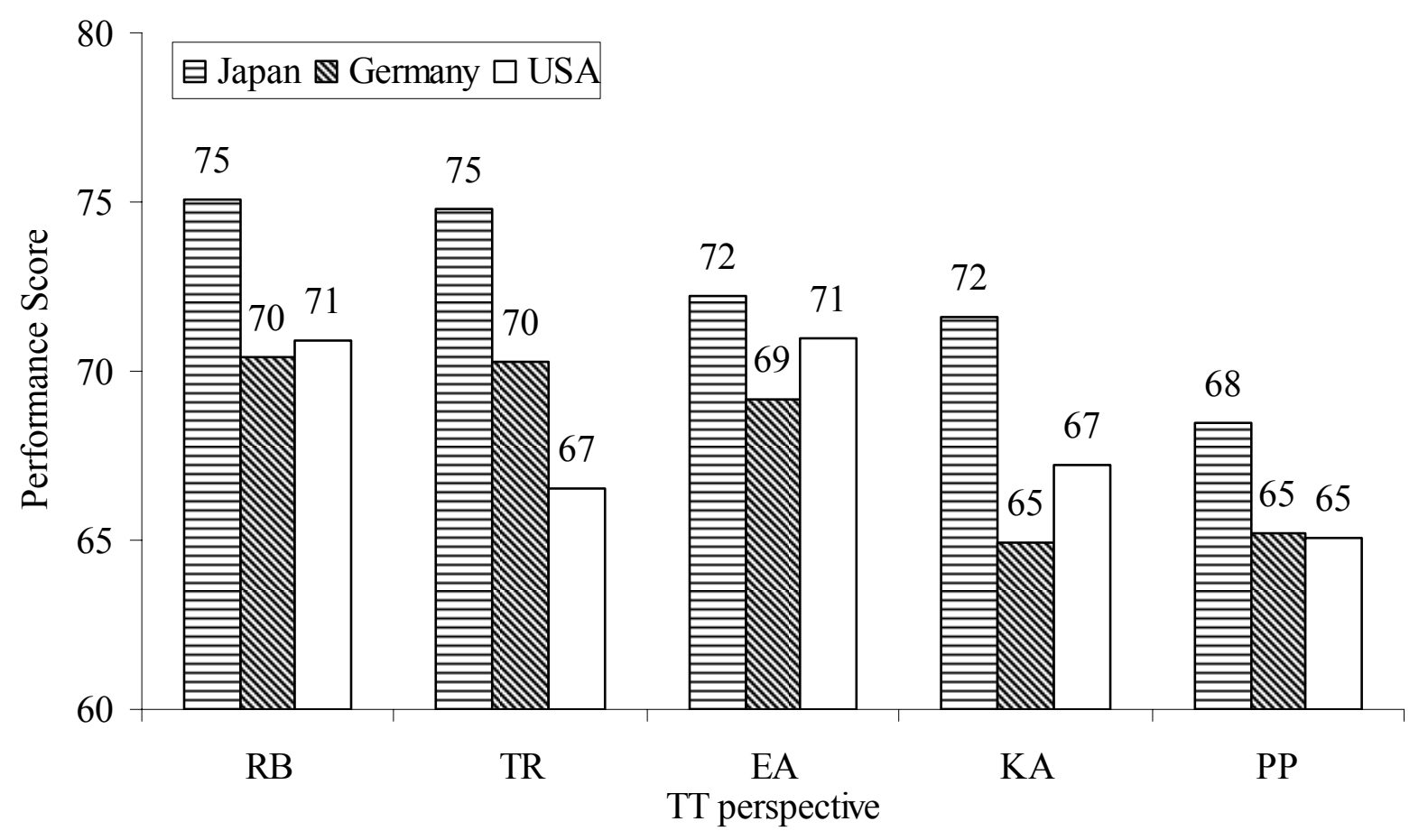

Figure 4 Comparative performance scores for perspectives influenced by transferor nationality 
Table 1 Technology transfer perspectives and indicators

\begin{tabular}{|c|c|c|}
\hline Perspectives & Description of indicators & References \\
\hline $\begin{array}{l}\text { Enablers } \\
\text { Transfer } \\
\text { environment }\end{array}$ & $\begin{array}{l}\text { Complexity of construction technology } \\
\text { Construction mode of transfer } \\
\text { Government policy } \\
\text { Government enforcement }\end{array}$ & $\begin{array}{l}\text { Calantone et al., 1990; } \\
\text { Kumaraswamy and Shrestha, } \\
\text { 2002; Ofori, 2000; Simkoko, } 1992\end{array}$ \\
\hline $\begin{array}{l}\text { Learning } \\
\text { environment }\end{array}$ & $\begin{array}{l}\text { Cultural differences } \\
\text { Trust } \\
\text { Communication } \\
\text { Understanding } \\
\text { Teamwork } \\
\text { Management commitment } \\
\text { Training programs } \\
\text { Engaging local sub-contractors in TT } \\
\text { Supervision of the TT process }\end{array}$ & $\begin{array}{l}\text { Black et al., 2000; Devapriya and } \\
\text { Ganesan, 2002; Fisher and } \\
\text { Ranasinghe, 2001; Kumaraswamy } \\
\text { and Shrestha, 2002; Lin and Berg, } \\
\text { 2001; Malik, 2002; Simkoko, } \\
\text { 1992; Wang et al., } 2004\end{array}$ \\
\hline $\begin{array}{l}\text { Transferor } \\
\text { characteristics }\end{array}$ & $\begin{array}{l}\text { Willingness to transfer technology } \\
\text { Level of experience } \\
\text { Cultural traits } \\
\text { Knowledge base }\end{array}$ & $\begin{array}{l}\text { Benedetto et al., 2003; Fisher and } \\
\text { Ranasinghe, 2001; Kumaraswamy } \\
\text { and Shrestha, 2002; Lin and Berg, } \\
\text { 2001; Makilouko, 2004; Malik, } \\
\text { 2002; Wang et al., 2004 }\end{array}$ \\
\hline $\begin{array}{l}\text { Transferee } \\
\text { characteristics }\end{array}$ & $\begin{array}{l}\text { Intent to learn technology } \\
\text { Level of experience } \\
\text { Cultural traits } \\
\text { Knowledge base }\end{array}$ & $\begin{array}{l}\text { Benedetto et al., 2003; Fisher and } \\
\text { Ranasinghe, 2001; Kumaraswamy } \\
\text { and Shrestha, 2002; Lin and Berg, } \\
\text { 2001; Makilouko, 2004; Malik, } \\
\text { 2002; Saad et al., 2002; Wang et } \\
\text { al., } 2004\end{array}$ \\
\hline $\begin{array}{l}\text { Value creation } \\
\text { Economic } \\
\text { advancement }\end{array}$ & $\begin{array}{l}\text { Competitiveness } \\
\text { Performance improvement }\end{array}$ & Benedetto et al., 2003 \\
\hline $\begin{array}{l}\text { Knowledge } \\
\text { advancement }\end{array}$ & $\begin{array}{l}\text { Improved knowledge } \\
\text { Improved working practices } \\
\text { Long-term adoption of transferred skills }\end{array}$ & $\begin{array}{l}\text { Gilbert and Cordey-Hayes, 1996; } \\
\text { Gold et al., } 2001\end{array}$ \\
\hline Project performance & $\begin{array}{l}\text { Financial performance } \\
\text { Schedule performance } \\
\text { Quality performance }\end{array}$ & $\begin{array}{l}\text { Chua et al., 1999; Devapriya and } \\
\text { Ganesan, } 2002\end{array}$ \\
\hline
\end{tabular}


Table 2 Varimax rotated factor loading for the eight-factor solution

\begin{tabular}{|c|c|c|}
\hline Perspectives & Indicators (identifying questions) & Factor Loading \\
\hline $\begin{array}{l}\text { Enablers } \\
\text { 1. Technology Characteristics } \\
\text { Variance }=3.53 \% \\
\text { Eigenvalue }=0.71 \\
\text { Cronbach's } \alpha=0.57\end{array}$ & $\begin{array}{l}\text { Complexity level } \\
\text { Construction mode of transfer }\end{array}$ & $\begin{array}{l}0.80 \\
0.84\end{array}$ \\
\hline $\begin{array}{l}\text { 2. Government Influence } \\
\text { Variance }=5.07 \% \\
\text { Eigenvalue }=1.01 \\
\text { Cronbach's } \alpha=0.81\end{array}$ & $\begin{array}{l}\text { Government policy } \\
\text { Government enforcement }\end{array}$ & $\begin{array}{l}0.90 \\
0.88\end{array}$ \\
\hline $\begin{array}{l}\text { 3. Relationship Building } \\
\text { Variance }=9.87 \% \\
\text { Eigenvalue }=1.97 \\
\text { Cronbach's } \alpha=0.79\end{array}$ & $\begin{array}{l}\text { Trust } \\
\text { Understanding } \\
\text { Communication }\end{array}$ & $\begin{array}{l}0.69 \\
0.75 \\
0.71\end{array}$ \\
\hline $\begin{array}{l}\text { 4. Transferor Characteristics } \\
\text { Variance }=34.97 \% \\
\text { Eigenvalue }=6.99 \\
\text { Cronbach's } \alpha=0.86\end{array}$ & $\begin{array}{l}\text { Willingness to implement } \\
\text { Transferor's degree of experience } \\
\text { Transferor management } \\
\text { Knowledge base }\end{array}$ & $\begin{array}{l}0.64 \\
0.76 \\
0.79 \\
0.72\end{array}$ \\
\hline $\begin{array}{l}\text { 5. Transferee Characteristics } \\
\text { Variance }=8.52 \% \\
\text { Eigenvalue }=1.70 \\
\text { Cronbach's } \alpha=0.77\end{array}$ & $\begin{array}{l}\text { Transferee's degree of experience } \\
\text { Transferee management } \\
\text { Knowledge base }\end{array}$ & $\begin{array}{l}0.84 \\
0.69 \\
0.65\end{array}$ \\
\hline $\begin{array}{l}\text { Value Creation } \\
6 . \text { Economic Advancement } \\
\text { Variance }=6.55 \% \\
\text { Eigenvalue }=1.31 \\
\text { Cronbach's } \alpha=0.83\end{array}$ & $\begin{array}{l}\text { Competitiveness } \\
\text { Performance }\end{array}$ & $\begin{array}{l}0.83 \\
0.79\end{array}$ \\
\hline $\begin{array}{l}\text { 7. Knowledge Advancement } \\
\text { Variance }=4.47 \% \\
\text { Eigenvalue }=0.89 \\
\text { Cronbach's } \alpha=0.77\end{array}$ & $\begin{array}{l}\text { Improved knowledge } \\
\text { Working practices }\end{array}$ & $\begin{array}{l}0.82 \\
0.69\end{array}$ \\
\hline $\begin{array}{l}\text { 8. Project Performance } \\
\text { Variance }=4.34 \% \\
\text { Eigenvalue }=0.87 \\
\text { Cronbach's } \alpha=0.70\end{array}$ & $\begin{array}{l}\text { Financial performance } \\
\text { Schedule performance }\end{array}$ & $\begin{array}{l}0.77 \\
0.80\end{array}$ \\
\hline
\end{tabular}


Table 3 Perspective and indicator mean and standard deviation

\begin{tabular}{|c|c|c|c|c|c|}
\hline Code & Perspectives - indicators & $\begin{array}{l}\text { Mean } \\
\text { Column A }\end{array}$ & $\begin{array}{l}\text { Std. dev. } \\
\text { Column A }\end{array}$ & $\begin{array}{l}\text { Mean } \\
\text { Column B }\end{array}$ & $\begin{array}{l}\text { Std. dev. } \\
\text { Column B }\end{array}$ \\
\hline TC & Technology characteristics & 3.42 & 0.83 & 3.30 & 0.70 \\
\hline TC1 & Complexity level & 3.48 & 0.82 & 3.24 & 0.65 \\
\hline TC2 & Mode of transfer & 3.36 & 0.84 & 3.36 & 0.74 \\
\hline GI & Government influence & 3.45 & 1.02 & 3.28 & 0.93 \\
\hline GI1 & Government policy & 3.41 & 1.04 & 3.26 & 0.87 \\
\hline GI2 & Government enforcement & 3.49 & 1.00 & 3.29 & 0.98 \\
\hline$R B$ & Relationship building & 4.05 & 0.87 & 3.62 & 0.93 \\
\hline RB1 & Trust & 3.92 & 0.83 & 3.44 & 0.91 \\
\hline RB2 & Understanding & 3.96 & 0.97 & 3.51 & 1.00 \\
\hline RB3 & Communication & 4.28 & 0.81 & 3.92 & 0.88 \\
\hline$T R$ & Transferor Characteristics & 3.97 & 0.79 & 3.63 & 0.86 \\
\hline TR1 & Willingness to implement & 3.99 & 0.82 & 3.57 & 0.98 \\
\hline TR2 & Degree of experience & 4.07 & 0.78 & 3.65 & 0.79 \\
\hline TR3 & Transferor management & 3.81 & 0.77 & 3.61 & 0.84 \\
\hline TR4 & Knowledge base & 4.01 & 0.77 & 3.67 & 0.83 \\
\hline$T E$ & Transferee Characteristics & 3.89 & 0.78 & 3.60 & 0.78 \\
\hline TE1 & Degree of experience & 3.88 & 0.82 & 3.62 & 0.82 \\
\hline TE2 & Transferee management & 3.76 & 0.79 & 3.54 & 0.77 \\
\hline TE3 & Knowledge base & 4.02 & 0.74 & 3.64 & 0.76 \\
\hline$E A$ & Economic advancement & 3.95 & 0.77 & 3.55 & 0.83 \\
\hline EA1 & Competitiveness & 3.94 & 0.77 & 3.50 & 0.81 \\
\hline EA2 & Performance & 3.95 & 0.77 & 3.59 & 0.85 \\
\hline$K A$ & Knowledge advancement & 3.85 & 0.79 & 3.44 & 0.91 \\
\hline KA1 & Improved knowledge & 3.77 & 0.82 & 3.34 & 0.89 \\
\hline KA2 & Working practices & 3.93 & 0.75 & 3.54 & 0.92 \\
\hline$P P$ & Project performance & 3.58 & 0.82 & 3.34 & 0.86 \\
\hline PP1 & Financial performance & 3.47 & 0.84 & 3.24 & 0.90 \\
\hline PP2 & Schedule performance & 3.69 & 0.79 & 3.44 & 0.81 \\
\hline
\end{tabular}


Table 4 Perspective and indicator mean and standard deviation - transferor nationality

\begin{tabular}{llllllll}
\hline \multirow{2}{*}{ Code } & \multirow{2}{*}{ Descriptions } & \multicolumn{2}{c}{ Japan $(N=45)$} & \multicolumn{2}{c}{ Germany $(N=26)$} & \multicolumn{2}{c}{ USA $(N=11)$} \\
\cline { 2 - 7 } & & Mean & Std. dev. & Mean & Std. dev. & Mean & Std. dev. \\
\hline RB & Relationship building & 3.72 & 1.05 & 3.49 & 0.98 & 3.52 & 0.74 \\
RB1 & Trust & 3.51 & 1.01 & 3.35 & 0.94 & 3.18 & 0.75 \\
RB2 & Understanding & 3.60 & 1.18 & 3.35 & 0.94 & 3.64 & 0.81 \\
RB3 & Communication & 4.04 & 0.95 & 3.77 & 1.07 & 3.73 & 0.65 \\
TR & Transferor characteristics & 3.70 & 0.97 & 3.48 & 0.81 & 3.29 & 0.80 \\
TR1 & Willingness to implement & 3.69 & 1.13 & 3.31 & 0.97 & 3.27 & 0.79 \\
TR2 & Degree of experience & 3.67 & 0.88 & 3.62 & 0.75 & 3.27 & 0.79 \\
TR3 & Transferor management & 3.64 & 0.98 & 3.58 & 0.70 & 3.27 & 0.79 \\
TR4 & Knowledge base & 3.80 & 0.89 & 3.42 & 0.81 & 3.36 & 0.81 \\
& & & & & & \\
EA & Economic advancement & 3.61 & 0.87 & 3.46 & 0.84 & 3.55 & 0.69 \\
EA1 & Competitiveness & 3.53 & 0.84 & 3.50 & 0.91 & 3.55 & 0.69 \\
EA2 & Performance & 3.69 & 0.90 & 3.42 & 0.76 & 3.55 & 0.69 \\
KA & Knowledge advancement & 3.56 & 0.97 & 3.24 & 1.10 & 3.36 & 0.67 \\
KA1 & Improved knowledge & 3.36 & 0.88 & 3.12 & 1.21 & 3.36 & 0.67 \\
KA2 & Working practices & 3.76 & 1.05 & 3.35 & 0.98 & 3.36 & 0.67 \\
PP & Project performance & 3.42 & 1.01 & 3.25 & 0.79 & 3.27 & 0.71 \\
PP1 & Financial performance & 3.36 & 1.09 & 3.19 & 0.69 & 3.36 & 0.67 \\
PP2 & Schedule performance & 3.47 & 0.92 & 3.31 & 0.88 & 3.18 & 0.75 \\
\hline & Overall mean & 3.62 & & 3.41 & & 3.39 & \\
\hline
\end{tabular}


Table 5 Evaluating technology transfer - baseline performance

\begin{tabular}{|c|c|c|c|c|c|c|c|}
\hline Perspective (relative weight) & Code & Indicator description & $\begin{array}{l}\text { Indicator } \\
\text { relative } \\
\text { weight } \\
r_{\mathrm{i}} \\
\end{array}$ & $\begin{array}{l}\text { Indicator } \\
\text { global } \\
\text { weight } \\
k_{\mathrm{i}} \\
\end{array}$ & $\begin{array}{l}\text { Indicator } \\
\text { performance } \\
\text { result } \\
x_{\mathrm{i}} \\
\end{array}$ & $\begin{array}{l}\text { Weighted } \\
\text { indicator } \\
\text { result } \\
r_{\mathrm{i}}\left(x_{\mathrm{i}}\right) \\
\end{array}$ & $\begin{array}{l}\text { Weighted } \\
\text { global } \\
\text { result } \\
k_{\mathrm{i}}\left(x_{\mathrm{i}}\right) \\
\end{array}$ \\
\hline \multirow[t]{3}{*}{ TC: Technology characteristics $(0.10)$} & $\mathrm{TC} 1$ & Complexity level & 0.57 & 0.057 & 3.24 & 1.85 & 0.1847 \\
\hline & $\mathrm{TC} 2$ & Mode of transfer & 0.43 & 0.043 & 3.36 & 1.44 & 0.1445 \\
\hline & & & & & $\mathrm{TC}$ & $3.29(66 \%)$ & \\
\hline \multirow[t]{3}{*}{ GI: Government influence $(0.10)$} & GI1 & Government policy & 0.46 & 0.046 & 3.26 & 1.50 & 0.1500 \\
\hline & GI2 & Government enforcement & 0.54 & 0.054 & 3.29 & 1.78 & 0.1777 \\
\hline & & & & & GI & $3.28(66 \%)$ & \\
\hline \multirow[t]{4}{*}{ RB: Relationship building $(0.15)$} & RB1 & Trust & 0.29 & 0.044 & 3.44 & 1.00 & 0.1496 \\
\hline & RB2 & Understanding & 0.30 & 0.045 & 3.51 & 1.05 & 0.1580 \\
\hline & RB3 & Communication & 0.41 & 0.062 & 3.92 & 1.61 & 0.2411 \\
\hline & & & & & $\mathrm{RB}$ & $3.66(73 \%)$ & \\
\hline \multirow[t]{5}{*}{ TR: Transferor characteristic $(0.20)$} & TR1 & Willingness to implement & 0.26 & 0.052 & 3.57 & 0.93 & 0.1856 \\
\hline & TR2 & Degree of experience & 0.28 & 0.056 & 3.65 & 1.02 & 0.2044 \\
\hline & TR3 & Transferor management & 0.20 & 0.040 & 3.61 & 0.72 & 0.1444 \\
\hline & TR4 & Knowledge base & 0.26 & 0.052 & 3.67 & 0.96 & 0.1908 \\
\hline & & & & & TR & $3.63(73 \%)$ & \\
\hline \multirow[t]{4}{*}{ TE: Transferee characteristic $(0.15)$} & TE1 & Degree of experience & 0.33 & 0.050 & 3.62 & 1.19 & 0.1792 \\
\hline & TE2 & Transferee management & 0.29 & 0.044 & 3.54 & 1.03 & 0.1540 \\
\hline & TE3 & Knowledge base & 0.38 & 0.057 & 3.64 & 1.38 & 0.2075 \\
\hline & & & & & $\mathrm{TE}$ & $3.60(72 \%)$ & \\
\hline \multirow[t]{3}{*}{ EA: Economic advancement $(0.10)$} & EA1 & Competitiveness & 0.50 & 0.050 & 3.50 & 1.75 & 0.1750 \\
\hline & EA2 & Performance & 0.50 & 0.050 & 3.59 & 1.80 & 0.1795 \\
\hline & & & & & EA & $3.55(71 \%)$ & \\
\hline \multirow[t]{3}{*}{ KA: Knowledge advancement $(0.10)$} & KA1 & Improved knowledge & 0.45 & 0.045 & 3.34 & 1.50 & 0.1503 \\
\hline & KA2 & Working practices & 0.55 & 0.055 & 3.54 & 1.95 & 0.1947 \\
\hline & & & & & KA & $3.45(69 \%)$ & \\
\hline \multirow[t]{4}{*}{ PP: Project performance $(0.10)$} & PP1 & Financial performance & 0.41 & 0.041 & 3.24 & 1.33 & 0.1328 \\
\hline & PP2 & Schedule performance & 0.59 & 0.059 & 3.44 & 2.03 & 0.2030 \\
\hline & & & & & $\mathrm{PP}$ & $3.36(67 \%)$ & \\
\hline & & & & & & TT index & $3.5067(70 \%)$ \\
\hline
\end{tabular}

